\title{
Gender differences in chronic obstructive pulmonary disease: Can be the DRG-based diagnosis the best way for a right analysis?
}

\author{
Antonello Nicolini, ${ }^{1}$ Giancarlo Garuti, ${ }^{2}$ Tommaso Perazzo, ${ }^{1}$ Paolo Banfi, ${ }^{3}$ Enrico Clini ${ }^{4}$ \\ ${ }^{1}$ Respiratory Diseases Unit, Hospital of Sestri Levante (GE); ${ }^{2}$ Pulmonology Unit, Hospital of Mirandola (MO); ${ }^{3}$ Rehabilitation \\ Pulmonology, Don Gnocchi Foundation, IRCCS, Milano; ${ }^{4}$ Pneumology Unit, University of Modena and Reggio Emilia, Italy
}

\section{Dear Editor,}

The diagnosis of chronic obstructive pulmonary disease (COPD) is usually made based on history and physical exam alone. Symptoms of dyspnea, cough and wheezing are non-specific and attributable to a variety of respiratory diseases. Confirmatory test to verify airflow obstruction is available ${ }^{1}$ but rarely used, which may result in substantial misdiagnoses of COPD. Overdiagnosis of COPD can occur in about $30 \%$ of patients admitted for COPD, above all in obese patients. ${ }^{2,3}$ Factors predictive of airflow obstruction include smoking status and higher pack-year history. Negative predictive factors include higher body mass index and other medical comorbidities such as congestive heart failure (CHF), obesity and obstructive sleep apnea. ${ }^{1}$

Underdiagnosis of COPD is also common and diagnostic confusion regarding COPD is more common in hospitalized patients than in outpatients. ${ }^{3}$ Identifying COPD patients earlier during their hospitalization is crucial for optimal care and readmission reduction. ${ }^{2,3}$ In this regard we have read with true interest the study by Ambrosino et al. who analyzed gender differences in patients discharged with diagnosis of COPD. ${ }^{4}$

Some observations are needed to better focus and understand the importance of the study:

Correspondence: Antonello Nicolini, Respiratory Diseases Unit, ASL4 Regione Liguria, via Terzi 43, 16039 Sestri Levante (GE), Italy.

Tel.: +39.018.5329145.

E-mail: antonellonicolini@gmail.com

Received for publication: 26 April 2019.

Accepted for publication: 2 May 2019.

This work is licensed under a Creative Commons Attribution NonCommercial 4.0 License (CC BY-NC 4.0).

${ }^{\circ}$ Copyright: the Author(s), 2019

Licensee PAGEPress, Italy

Italian Journal of Medicine 2019; 13:187-188

doi:10.4081/itjm.2019.1175
- The population (COPD with exacerbation or without exacerbation) was selected following ICD-9$C M$ codes: there is no mention either of diagnostic tool (spirometry) or of risk factors (smoking or other factors). Moreover, it is not clear if the diagnosis of COPD has been made upon hospital admission or if it was available previously. ${ }^{5}$ As reported above, a large percentage of hospital diagnosis of COPD is not supported by a documentation of spirometry. The mean of COPD diagnosis confirmed by spirometry is ranging between $10-40 \%{ }^{6}$

- Comorbidities: the presence of comorbidities such as heart failure and above all obesity makes difficult a differential diagnosis between an exacerbation of COPD with an exacerbation of CHF and a decompensation of obesity hypoventilation syndrome (OHS), an entity frequently and highly misdiagnosed. ${ }^{7}$

- Severity of illness: we have not found any mention about severity of illness (GOLD stage) or of association with respiratory failure. It can be an important bias regarding hospital mortality. Furthermore, some studies which have evaluated gender differences in COPD patients, have considered GOLD stage and post-bronchodilator spirometry ${ }^{8}$ or spirometry and arterial blood gases. ${ }^{9}$

- Regarding respiratory therapy code (ICD-993.9x), it is not clear if it was performed in acute COPD patients or in stable patients. As known respiratory physiotherapy can improve the outcome also in acute exacerbations of COPD. ${ }^{10}$

In conclusion studies on hospitalized patients with COPD should include confirmatory pulmonary function tests, ${ }^{11}$ and if possible, its severity according to GOLD stages. It can help reduce COPD overdiagnosis, especially among OHS and CHF patients, who often present an episode of decompensation not easily discernible from an exacerbation of COPD. ${ }^{7} \mathrm{We}$ think that only with a confirmed and established diagnosis, it is possible to perform a comparative analysis of different populations (i.e., males and females) of hospitalized patients regarding clinical outcomes such as length of hospital stay, hospital readmission and mortality. 


\section{References}

1. Global Initiative for Chronic Obstructive Lung Disease. Global strategy for the diagnosis, management, and prevention of chronic obstructive pulmonary disease: NHLBI/WHO workshop report; 2018. Available from: http://www.goldcopd.com/

2. Spero K, Bayasi G, Beaudry L, et al. Overdiagnosis of COPD in hospitalized patients. Int $\mathrm{J}$ COPD 2017; 12:2417-23.

3. Centurion VP, Huang F, Naureckas E, et al. Confirmatory spirometry for adult hospitalized with a diagnosis of asthma or chronic obstructive pulmonary disease exacerbation. BMC Pulm Med 2012;12:73.

4. Ambrosino I, Gallone MS, Patano F, et al. Gender differences in chronic obstructive pulmonary disease : an analysis of hospitalization indicators. Ital J Med 2019;13:1099.

5. Smyth ET, Wright SC, Evans AE, et al. Death from airways obstruction: accuracy of certification in Northern Ireland. Thorax 1996;51:293-7.
6. Lusuardi M, Garuti G, Massobrio M, et al. The auditintervention-reaudit cycle can improve diagnostic standard for chronic obstructive pulmonary disease (COPD). Intern Emerg Med 2014;9:113-4

7. Sequeira TCA, BaHammam A, Esquinas AM. Noninvasive ventilation in the critically ill patient with obesity hypoventilation syndrome: a review. J Intensive Care Med 2016 [Epub ahead of print].

8. Dal Negro RW, Bonadiman L, Turco P. Prevalence of different comorbidities in COPD patients by gender and GOLD stage. Multidisc Resp Med 2015;10:24.

9. Moretti AM, Gallone MS, Parisi D, et al. Gender differences and hospitalization for COPD: an analysis of the data from Puglia (Italy). Ital J Gender-Specific Med 2015;1:66-72.

10. Spencer L. Pulmonary rehabilitation for patients with acute chronic obstructive pulmonary disease exacerbations: is the evidence strengthening. Curr Opin Pulm Med 2018;24:147-51.

11. Rea H, Kenealy T, Adair J, et al. Spirometry for patients in hospital and one month after admission with an acute exacerbation. Int J COPD 2011;6:527-32. 